Check for updates

Cite this: RSC Adv., 2017, 7, 41017

Received 14th July 2017

Accepted 9th August 2017

DOI: 10.1039/c7ra07756d

rsc.li/rsc-advances

\section{Redefining Chinese calligraphy rice paper: an economical and cytocompatible substrate for cell biological assays}

\author{
Ying Zhou, $\uparrow^{\text {ab }}$ Jing Jing Fu, $\dagger^{\text {ab }}$ Ying Shuai Liu, (D) ab Yue Jun Kang, (D) ab \\ Chang Ming $\mathrm{Li}(\mathbb{D}$ *ac and Ling Yu (D) *ab
}

Paper is a permeable porous material composed of a solid network of fibers. It is cheap, abundant, disposable and recyclable and has self-powered fluid wicking properties that are useful in building analytical devices. Paper-based cell assays are still in their infancy compared with enzyme- and proteinbased analyses. For the first time, we show the potential of rice paper (an organic paper specifically used in Chinese calligraphy) for building cell analysis platforms. Rice paper's solution wicking and surface characterizations prove that it has a similar chemical configuration as that of a standard Whatman filter paper. Moreover, lactate dehydrogenase (LDH) release assay and WST-1 cell growth assay show that rice paper has better cell-compatibility features and improved cell distribution. The cell anchors and spreads along the cellulose fiber of the rice paper, whereas the porous rice paper matrix provides a sufficient surface area for cell growth. Cell-based immunohistochemistry was conducted to measure the expression of $\mathrm{O}$-linked $\mathrm{N}$-acetylglucosamine (O-GlcNAc) protein on prostate cancer cell DU145. An enhanced colorimetric signal was observed from cells grown on rice paper-based cell culture platform than those grown on 2D culture dish. The feasibility of fabricating rice paper with both direct crafting and wax printing-as well as on-paper cell immunoassays for on-demand applications-confirms the potential of rice paper as a new substrate for building paper devices for cell biology studies.

\section{Introduction}

Paper as an economical and biocompatible substrate to build biochemical analysis tools has recently attracted tremendous attention. $^{\mathbf{1 - 3}}$ Versatile paper-based microfluidic analytical devices have been innovated for point-of-care diagnosis, food safety and environment supervision. ${ }^{4-6}$ The first cell-based application of paper wherein a cell-in-gels-in-paper (CiGiP) model was developed by Dr Whitesides in 2009. ${ }^{7}$ It was reported that the advantageous characteristic of paper, as a low-cost and abundant material to study 3D models, is that it can be stacked and de-stacked to reveal the inner 3D morphology. Since then, the CiGip technique has been expanded to build different platforms for cell assays and people have studied cell growth, migration and differentiation using paper-based tools. Remarkably, the CiGiP model has been applied to investigate

\footnotetext{
Institute for Clean Energy \& Advanced Materials, Faculty of Materials \& Energy, Southwest University, Chongqing 400715, China. E-mail: lingyu12@swu.edu.cn; ecmli@swu.edu.cn

${ }^{b}$ Chongqing Key Laboratory for Advanced Materials and Technologies of Clean Energies, Chongqing 400715, China

${ }^{c}$ Institute for Materials Science and Devices, Suzhou University of Science and Technology, Suzhou 215011, P. R. China

$\dagger$ Contribute equally to this work.
}

interactions between fibroblasts and human lung cancer, ${ }^{8}$ chemotaxis of cancer cells in an oxygen gradient, ${ }^{9}$ and differentiation of human-induced pluripotent stem cells. ${ }^{10}$ In addition, a paper sheet has been fabricated into versatile microdevices to investigate cellular phosphorylation, ${ }^{11}$ biomineralization of artificial bone tissues, ${ }^{12}$ and high-throughput testing of the effect of soluble compounds. ${ }^{13}$ Paper as a substrate for a cell culture platform and its emerging biomedical applications has been well reviewed by $\mathrm{Dr} \mathrm{Xu}^{\mathbf{1 4}}$ and Dr Cheng. ${ }^{15}$ Although distinct stacking and destocking procedure to build a 3D culture model demonstrated the potential of paper-based devices for cell-based studies, it is of importance to observe that the paper of choice is limited to certain types of paper; the most popular are Whatman brand 114 chromatography filter paper (CFP-114) and lens paper (LP). Whatman CFP114 paper is quite thick $(\sim 200 \mu \mathrm{m})$, and this affects microscopy studies. Lens paper is $\sim 40 \mu \mathrm{m}$ thick. Because of its looser cellulose matrix, two pieces of lens paper are normally laminated to one paper layer to avoid disassembling of the fiber networks. ${ }^{8}$ Qin et al. compared the impact of print papers, chromatography/filter papers, and nitrocellulose membranes on human-induced pluripotent stem cell differentiation. ${ }^{10}$ The results confirm that the paper's chemical and physical properties such as roughness, pore (microspace) diameters, or density can modulate cell growth. 
The weakness of the current materials and the distinct merits of paper as a platform for cell-based assay drive us to look for a new type of paper substrate for the construction of paper-based cell analysis platforms. Chinese calligraphy paper, also known as rice paper or Xuan Zhi, has been used for writing in China since the middle of the third century B.C.E. It is made of materials such as rice, mulberry, bamboo, and hemp. Herein, we evaluate the potential of rice paper for cell analysis by studying its morphology, thickness, and wettability. The fabrication of rice paper was evaluated with wax printing and direct crafting, two of the most common approaches for fabricating paper-based microanalytical devices. Moreover, the cell-analysis compatibility was shown to support cell growth and adhesion. Finally, cell-based immunohistochemistry has been demonstrated through the analysis of the $\mathrm{O}-\mathrm{N}$-acetylgalactosamine $(\mathrm{O}$ GalNAc) protein expressed by prostate cancer cells.

\section{Experimental}

\subsection{Materials and reagents}

Prostate cancer cells (DU145) were generously donated by Dr Li Yuan, Chongqing Medical University. The cells were maintained in DMEM medium (Gibco) containing 10\% fetal bovine serum (Gibco), penicillin (100 $\left.\mathrm{U} \mathrm{mL}^{-1}\right)$ and streptomycin (100 $\mu \mathrm{g} \mathrm{mL} \mathrm{m}^{-1}$ ) at $37{ }^{\circ} \mathrm{C}$ in $5 \% \mathrm{CO}_{2}$ atmosphere. Fluorescein isothiocyanate-labeled phalloidin (FITC-phalloidin), 2-(4amidino-phenyl)-6-indolecarb-amidinedihydro-chloride (DAPI), WST-1 proliferation kit, lactate dehydrogenase (LDH) cytotoxicity assay kit and haematoxylin and eosin stain (H\&E stain) kit were purchased from Beyotime Biotechnology (Beijing, China).

Rabbit anti-O-GalNAc antibody was from Abcam (USA). HRPlabelled anti-rabbit IgG antibody was ordered from Cell Signalling Technology (USA). Selective O-GlcNAcase inhibitor Thiamet $\mathrm{G}$ solution, Whatman brand chromatography filter paper (CFP, no. 114) and lens paper (LP, no. 105) were obtained from Sigma Aldrich (USA). Rice paper with different thickness was purchased from a book store. All other chemicals were purchased from Aladdin Chemical Reagent Co., Ltd., China and used without further purification unless otherwise indicated. All solutions were prepared with deionized water produced by PURELAB flex system, ELGA Corporation.

\subsection{Paper characterization}

The morphology of the paper substrate was characterized by a VK-V150 laser microscopy system (Keyence, Japan). The surface chemical properties of the paper specimens were measured by a Fourier transform spectrophotometer (ThermoNicolet Model 6700, Tokyo, Japan). X-ray diffraction (XRD) measurements were performed on a MAXima-X XRD-7000 system in a $2 \theta$ range between $10^{\circ}$ and $80^{\circ}$ to identify the crystalline phase of the paper specimens. The wettability of the paper substrate was evaluated by measuring the flow rate on a paper strip. Briefly, paper specimens were cut into strips ( $8.5 \mathrm{~cm}$ long and $0.5 \mathrm{~cm}$ wide). These were firmly laminated on a piece of Parafilm ${ }^{\circledR}$. Then, $30 \mu \mathrm{L}$ of liquid was pipetted onto one end of the paper strip. The solution wicking distance on the strip was measured and compared.

\subsection{Fabrication of paper device for cell-based assay}

We used two common paper fabrication methods. (1) Crafting: versatile structures were designed and crafted using a desktop cutter (Silhouette Portrait, Silhouette America, Inc., USA). Otherwise, the rice paper can be directly shaped by a paper shaper punch, i.e., a low-cost office tool. (2) Wax printing: wax patterns were directly printed on rice paper via a wax printer (Fuji Xerox, ColorQube 8580, Japan). The paper specimens were then placed in an oven at $150{ }^{\circ} \mathrm{C}$ for 30 seconds. Before the cell assay, all the paper devices were sterilized with ethanol immersion and UV light irradiation. The paper disc was then ready for cell-based experiments.

\subsection{Cell compatibility of the rice paper}

Cell cytotoxicity assay. The lactate dehydrogenase (LDH) activity assay was evaluated to study the level of cell damage, which can be indirectly indicated by the amount of LDH released into the culture medium. To test the cell compatibility of the rice paper, a cell suspension with a density of approximately $5.0 \times 10^{5}$ cells per $\mathrm{mL}$ was seeded in a Petri dish containing a paper disc (diameter $=1.5 \mathrm{~cm}$ ) and incubated at $37^{\circ} \mathrm{C}$ in a $5 \% \mathrm{CO}_{2}$ atmosphere. The cell supernatant was collected after $48 \mathrm{~h}$ of culturing and analyzed with an LDH assay kit following the manufacturer's protocol. In brief, the supernatant was incubated with the reaction mixture from the kit for $30 \mathrm{~min}$ and then the absorbance was measured at $490 \mathrm{~nm}$ in a microplate reader (ELx800TM, Gene Company) with a reference wavelength of $630 \mathrm{~nm}$. All the experiments were performed three independent times.

Cell proliferation assay. To analyze cell proliferation on the rice paper, $150 \mu \mathrm{L}$ of a DU145 cell suspension with a density of approximately $1.0 \times 10^{5}$ cells per $\mathrm{mL}$ was seeded in paper discs placed in a 96 well-microplate and incubated at $37^{\circ} \mathrm{C}$ in a $5 \%$ $\mathrm{CO}_{2}$ atmosphere. After $72 \mathrm{~h}$ of incubation, the cell proliferation was characterized with a WST-1 assay according to the manufacturer's instructions. In brief, the paper discs were washed with PBS and placed in a new micro-well plate. The fresh medium plus WST-1 reagent was added into each well and incubated at $37^{\circ} \mathrm{C}$ for $4 \mathrm{~h}$. Finally, the absorbance at $450 \mathrm{~nm}$ was measured with a reference wavelength of $630 \mathrm{~nm}$. All the experiments were performed three times.

Cell adhesion assay. To measure cell adhesion, a cell suspension with a density of approximately $5.0 \times 10^{5}$ cell per $\mathrm{mL}$ was seeded into a micro-plate wherein paper discs (diameter $=1.5 \mathrm{~cm}^{2}$ ) were arranged. After incubating at $37^{\circ} \mathrm{C}$ for $0,3,12$ and $24 \mathrm{~h}$ in a $5 \% \mathrm{CO}_{2}$ atmosphere, the paper discs were washed with PBS to remove non-adherent cells. The adherent cells were fixed with $4 \%$ paraformaldehyde and stained with hematoxylin and eosin (H\&E). Finally, the adherent cells of six randomly selected fields per paper disc were imaged using a microscope. All the experiments were performed three independent times.

Fluorescent staining of cells grown on rice paper. Cells were cultured on paper specimens for $48 \mathrm{~h}$, then fixed in $4 \%$ 
paraformaldehyde in $1 \times$ PBS for $30 \mathrm{~min}$ at room temperature. Then, after 3 washes with $1 \times$ PBS, the cells were permeabilized with $0.1 \%$ Triton $\mathrm{X}-100$ in $1 \times$ PBS for $10 \mathrm{~min}$ at room temperature. For filamentous actin staining, FITC-phalloidin solution (1 : 50, Beyotime Biotechnology) was added, incubated at $4{ }^{\circ} \mathrm{C}$ for $60 \mathrm{~min}$, and washed 3 times with PBS. Then, nuclei staining

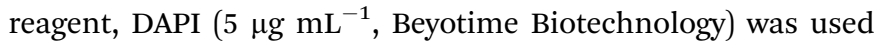
following standard protocols. Finally, the cells in the paper specimens were imaged on a confocal microscope (ZEISS LSM 800 , German).

\subsection{Rice paper-based cell immunoassay for measuring $\mathrm{O}-\mathrm{N}$ - acetylgalactosamine ( $O$-GalNAc) expressed by prostate cancer cells}

Herein, $100 \mu \mathrm{L}$ of the prostate cancer cell DU145 at $1.0 \times 10^{5}$ cells per $\mathrm{mL}$ was seeded in a paper disc and incubated at $37{ }^{\circ} \mathrm{C}$ for 1 day. At the end of day 1, the paper discs were washed with PBS to remove the non-adherent cells. The cell-loaded paper discs were then placed in a new cell-culture plate filled with fresh culture medium and cultured for another $24 \mathrm{~h}$. Then, the treatment was performed by applying $10 \mu \mathrm{L}$ of selective $O$-GlcNAcase inhibitor Thiamet G solution ( $5 \mathrm{mM}$ ) to each cellloaded paper disc. After $24 \mathrm{~h}$ culturing, the cells on the paper were then fixed with $4 \%(\mathrm{w} / \mathrm{v})$ paraformaldehyde in PBS for $15 \mathrm{~min}$ at room temperature. After permeabilizing the cells with $0.1 \%(\mathrm{v} / \mathrm{v})$ Triton-100 in PBS for $10 \mathrm{~min}$ at room temperature, the samples were incubated with a membrane-blocking reagent (Beyotime Biotechnology, China) at room temperature for $1 \mathrm{~h}$ to block non-specific antibody binding. The cell-loaded paper discs were then incubated with rabbit anti-O-GalNAc antibody (diluted $1: 200$, Abcam) at $4{ }^{\circ} \mathrm{C}$ overnight. Then, horseradish peroxidase (HRP)-conjugated goat anti-rabbit secondary antibodies (diluted 1 : 1000, Cell Signaling Technology, USA) in PBS were added to the paper disc for $0.5 \mathrm{~h}$ at room temperature after which the samples were washed with PBS 3 times for $5 \mathrm{~min}$ each. Finally, the precipitated $3,3^{\prime}, 5,5^{\prime}$-tetramethylbenzidin (TMB) substrate was added to the paper disc, and the colorimetric changes were imaged with a camera. A paper disc without cell loading was set as the background control. The concentration of the $O$-GalNAc protein was correlated to the color intensity within the paper discs. The on-paper immunoassay results were further analyzed with an ImageJ (NIH, USA). First, the colour images were separated into red, blue and green channel. The intensity of red channel was retrieved. Furthermore, the colorimetric signal was represented by the changes of red channel intensity using the background control as a reference. All the experiments were performed three times.

\section{Results and discussion}

3.1 Sufficient solution wicking capability, clear cellulose component and processibility of rice paper support fabrication of paper device for cell analysis

The primary goal of this study was to evaluate the potential of rice paper as a new substrate for paper-based cell chips. Rice paper can be raw, semi-raw, or mature. In calligraphy practicing, raw paper is highly absorbent. It is the most desirable paper for calligraphy art due to its outstanding blurring abilities. Semi-raw and mature (sized) papers are often chemically coated with an alum solution. As shown in Fig. 1A, the solution diffuses faster within raw rice paper compared with semi-raw and mature papers. In this study, raw rice paper (RRP) with different thickness was used because of its solution absorbability and non-chemical coating. In this following text, rice paper is referred to as raw rice paper for simplicity. The wettability of the RRP was evaluated in terms of flow wicking speed. Fig. 1B shows that the same volume of liquid pipette on the paper strips resulted in different flow wicking distances. On examining the solution wicking distance, it was observed that raw rice paper ( $60 \mu \mathrm{m}$ to $120 \mu \mathrm{m}$ thick) has comparable solution wicking distance as chromatography paper and lens paper.

The chemical composition of the paper specimens was characterized by FTIR and XRD measurement. As shown in Fig. 1C, FTIR spectrum of chromatography filter paper exhibits characteristic peaks at 3400 and $2920 \mathrm{~cm}^{-1}$ because of $\mathrm{O}-\mathrm{H}$ stretching and $\mathrm{C}-\mathrm{H}$ stretching vibrations of cellulose. The characteristic peaks appear at 1424 and $1030 \mathrm{~cm}^{-1}$ denoting $\mathrm{C}-\mathrm{H}$ bending and $\mathrm{O}-\mathrm{H}$ bending vibrations, respectively. ${ }^{16}$ The same characteristic peaks of cellulose are observed from all RRP specimens. In addition, the XRD results show a distinct peak with $2 \theta$ values of $15.6^{\circ}$ and $22.5^{\circ}$ (marked with ${ }^{*}$ ) that are attributed to cellulose from all rice paper specimens and lens paper, confirming the similar degree of crystallization of cellulose within raw rice paper and lens paper (Fig. 1D). ${ }^{17}$ However, from the XRD pattern of chromatography filter paper,
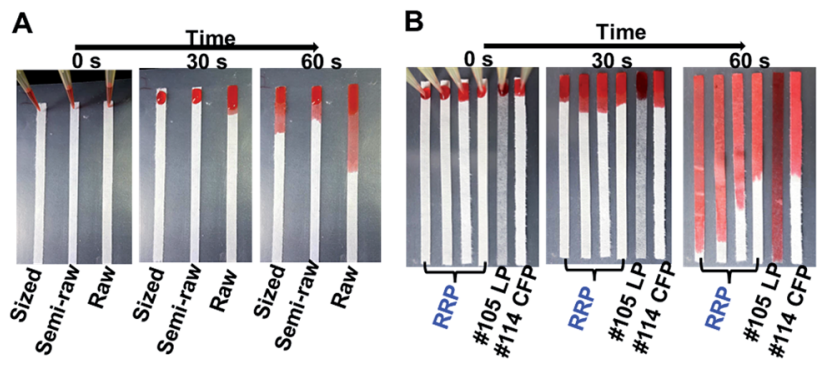

C

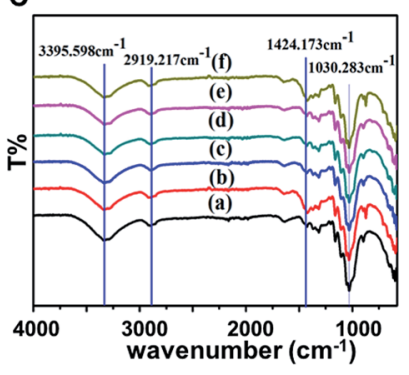

D

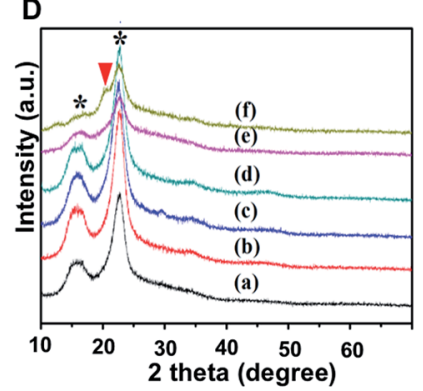

(a) Rice paper - $60 \mu \mathrm{m}$; (b) Rice paper - $80 \mu \mathrm{m}$; (c) Rice paper - $100 \mu \mathrm{m}$; (d) Rice paper - $120 \mu \mathrm{m}$; (e) Lens paper \#105; (f) Chromatography filter paper \#114

Fig. 1 Characterization of paper specimens. (A) Solution wicking distance on sized, semi-raw and raw rice paper; (B) solution wicking distance on raw rice paper (RRP)-thickness $=60,80,100,120 \mu \mathrm{m}$ (from left to right), Whatman brand \# 105 lens paper (LP) and Whatman brand \# 114 chromatography paper (CFP); (C) the FTIR spectra of paper specimens; (D) the XRD patterns of paper specimens. 


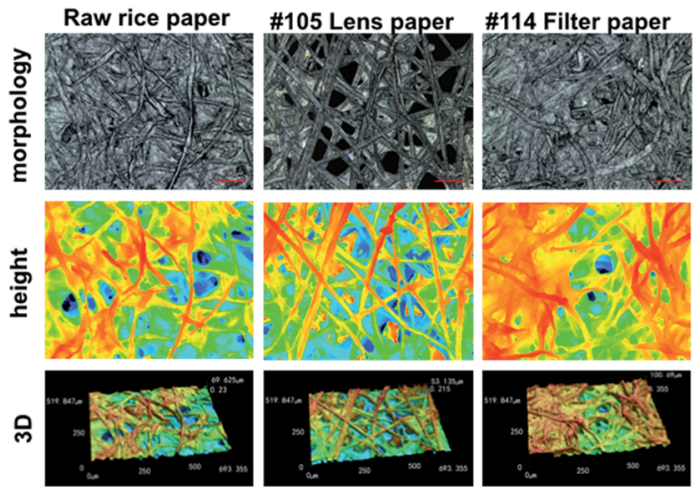

Fig. 2 The morphology of paper specimens characterized by laser microscopy.

there is a small peak at the shoulder of the main cellulose peak at $22.5^{\circ}$, indicating existence of non-cellulose component in chromatography filter paper.

The morphology and roughness of the rice paper were characterized by a laser microscopy system (Keyence VK-V150, Japan). In all paper specimens, a 3D matrix was formed by cellulose fibers (Fig. 2). The surface roughness $\left(R_{\mathrm{a}}\right)$ of the raw rice paper, lens paper and filter paper are $8.14 \pm 3.34 \mu \mathrm{m}, 7.37 \pm 0.98 \mu \mathrm{m}$ and $10.27 \pm 2.51 \mu \mathrm{m}$, respectively. Moreover, from the height image characterization, more cavities can be observed for the fiber matrix of rice paper and lens paper. The cave formed between cellulose fiber could be the path for cell moving and solution permeating. In addition, because of the thickness difference, the diffusion of nutrients from cell culture medium could be faster in rice paper (60-120 $\mu \mathrm{m}$ and lens paper $(40 \mu \mathrm{m}))$ than in thicker chromatography paper $(\sim 200 \mu \mathrm{m})$. The ease of solution transportation within the paper matrix could further facilitate the growth of cells.

The micro-fabrication and processing of rice paper was examined by two widely used methods for preparing paper-based analytical devices. First, paper was shaped with a simple paper
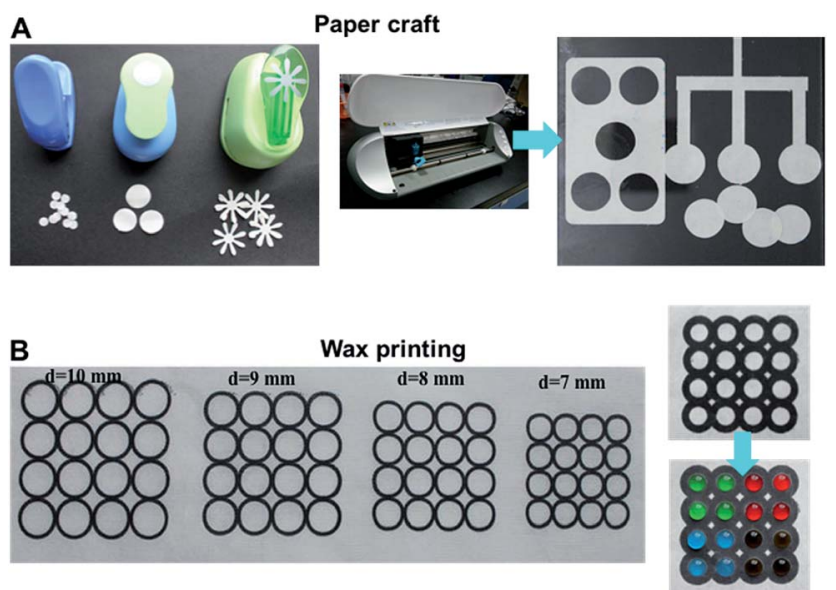

Fig. 3 Processibility of raw rice paper for building paper based devices. (A) The paper can be directly shaped by a paper cutter; (B) hydrophobic and hydrophilic regions can be patterned on raw rice paper by wax printing.

A
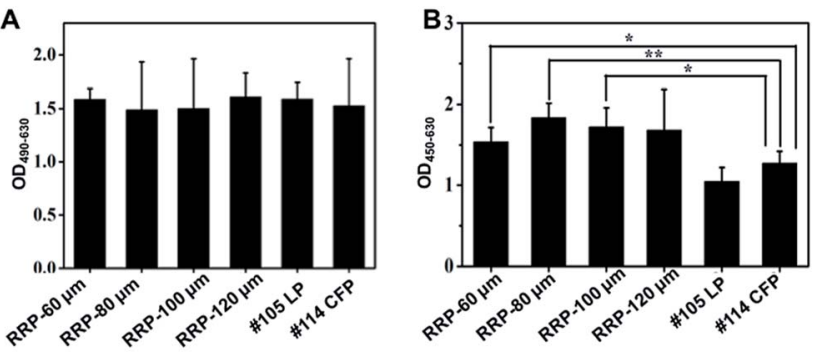

C
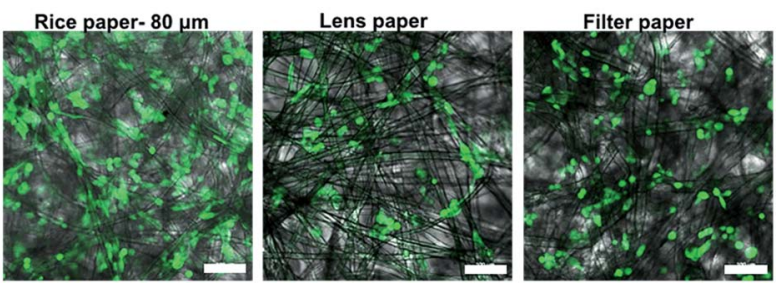

Fig. 4 Cytocompatibility of raw rice paper. (A) LDH release assay to characterize cytotoxicity of paper specimens; (B) WST-1 assay to characterize the cell proliferation on paper specimens; * denotes $p<$ $0.05, * *$ denotes $p<0.01$; (C) cells distribution on cellulose fiber characterized by confocal microscopy. Scale bar $=100 \mu \mathrm{m}$.

shaper punch or a desktop paper cutter (Silhouette Portrait, USA). The results prove that cutting, a straightforward approach, can be used to prepare rice paper artwork of various shapes (Fig. 3A). Wax patterning via commercial wax printers is a popular approach to forming hydrophobic barriers on a paper. Fig. 3B shows that solid wax lines can be printed on a rice paper sheet. These are then heat-melted to form a wax barrier on the paper. The smallest round zone that can be formed on raw paper is $0.2 \mathrm{~cm}$ in diameter. The separated zone on the raw paper can then be used for cell array applications. The feasibility of the rice paper for both paper crafting and wax printing confirms its utility in building low-cost platforms for cell analysis.

\subsection{Vigorous cell anchoring and proliferation on rice paper}

Cellulose fiber networks offer a 3D matrix to support cell growth. The cell compatibility of the raw rice paper was evaluated by analyzing the impact of paper specimens on cell cytotoxicity, proliferation, and adhesion. To demonstrate the cellcompatibility of the rice paper, Whatman brand filter paper and lens paper were used as standards. Fig. 4A plots LDH release, which reflects the cell membrane integrity; more LDH implies higher cytotoxicity. The results show that there is no significant difference between the rice paper group and the filter paper group over 2 days of culture. This indicates comparable cell-compatibility as Whatman 114 filter paper. Next, the WST-1

Table 1 Cost of paper specimens in this study

\section{Paper specimens}

Raw rice paper

Whatman \# 105 lens paper

Whatman \# 114 filter paper
Price per $100 \mathrm{~cm}^{2}$ (RMB)

0.02 Yuan

1.20 Yuan

2.40 Yuan 


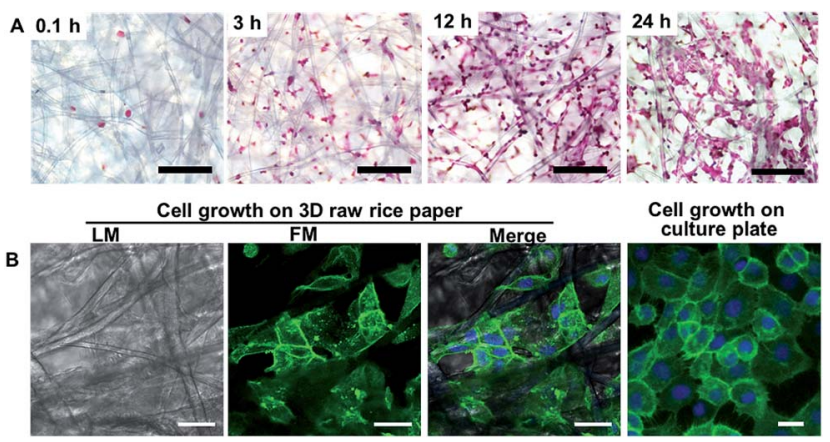

Fig. 5 Cells anchoring and spreading on cellulose fiber of raw rice paper. (A) DU145 cells adhesion on raw rice paper. Hematoxylin and eosin stained cells after $0.1,3,12$ and $24 \mathrm{~h}$ growth on raw rice paper; scale bar $=100 \mu \mathrm{m}$. (B) Fluorescent characterization of DU145 cells growth on substrate. After $24 \mathrm{~h}$ of culture, the cells grown on the raw rice paper and standard culture plate were stained with FITC-labeled phalloidin (green) and DAPI (blue); scale bar $=10 \mu \mathrm{m}$.

assay was conducted to monitor cell proliferation on paper specimens. It indicates that more cells grew from rice paper, particularly from RRP-60 $\mu \mathrm{m}$ to RRP-80 $\mu \mathrm{m}$ (Fig. 4B). The fluorescent microscopy image in Fig. 4C shows a higher cell distribution density for rice paper than that for filter and lens papers. Moreover, in previous studies, cells were encapsulated in a gel to ensure uniform distribution anchoring in the cell matrix.4-6 However, without hydrogel assistant-cell encapsulation and seeding, cells can uniformly grow on rice paper. Collectively, the material characterization (FTIR and XRD) and the cytocompatibility evaluation (LDH and WST-1 assay) results prove that the main component of the raw rice paper is cellulose fiber, and it exhibits better cell compatibility compared with Whatman brand filter and lens papers. The cost of rice paper is only one percent of that of Whatman filter paper (Table 1). In addition, the thickness of rice paper varies $(60-120 \mu \mathrm{m})$, offering more selections for customized applications. Microscopy is well-established for biological assays, and a new substrate for cell culture should try to satisfy the needs of microscopy observation. Thus, in the following assay, $80 \mu \mathrm{m}$-thick RRP was chosen to balance microscopy's optical needs with sufficient mechanical stability.

To further depict the cell growth behaviour on RRP, the cell adhesion and cell skeleton were studied via fluorescent staining. The H\&E staining images show that cells anchoring on rice paper can be observed after $3 \mathrm{~h}$ of incubation (Fig. 5A). Seeding the cells on rice paper for $12 \mathrm{~h}$ permits sufficient cell anchoring and consequently cell proliferation (Fig. 5A). In addition, uniformly distributed cells also can be observed in the H\&E staining image. The cell skeleton was characterized under confocal microscopy and clearly shows the cells anchored on the cellulose fiber with spreading along the axis (Fig. 5B). Cells proliferating on rice paper show similar morphology and skeletal arrangement as previously observed in flat culture flasks (Fig. 5B). Compared to the 2D flat flask and culture dishes, rice paper has a significantly enlarged surface area and it can provide a porous cellulose matrix for cell anchoring and growth. In addition, the fluid permeability and porosity ensure that the culture medium and oxygen diffuse freely within the paper matrix to support cell growth.

\subsection{Low-cost rice paper platform for analyzing cytoplasmic $\mathrm{N}$-Nac polysaccharide production in prostate cancer cells}

$O$-Linked $\mathrm{N}$-acetylglucosamine $(\mathrm{O}$-GlcNAc) is a posttranslational modification comprising the addition of a sugar moiety to serine/threonine residues of cytosolic or nuclear proteins. ${ }^{18}$ The
A
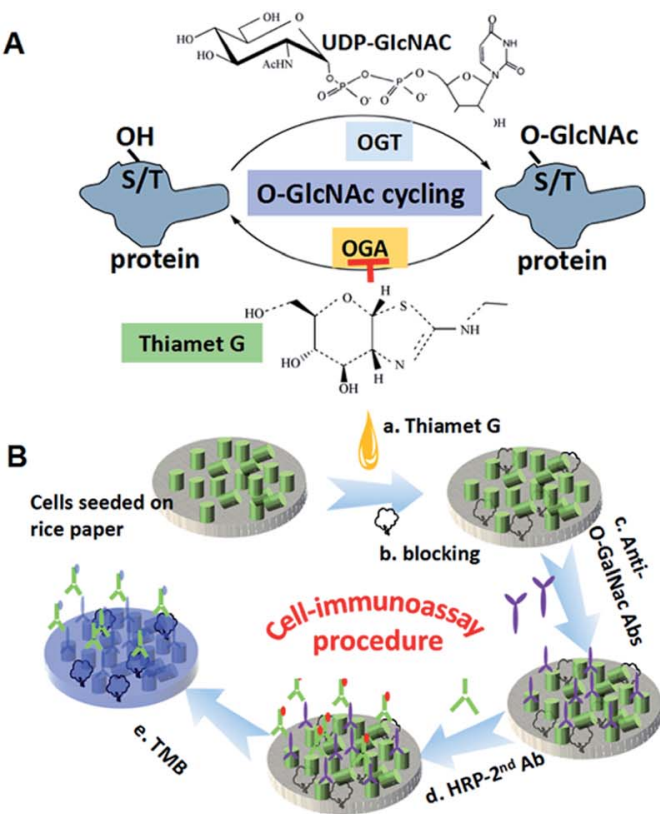

C
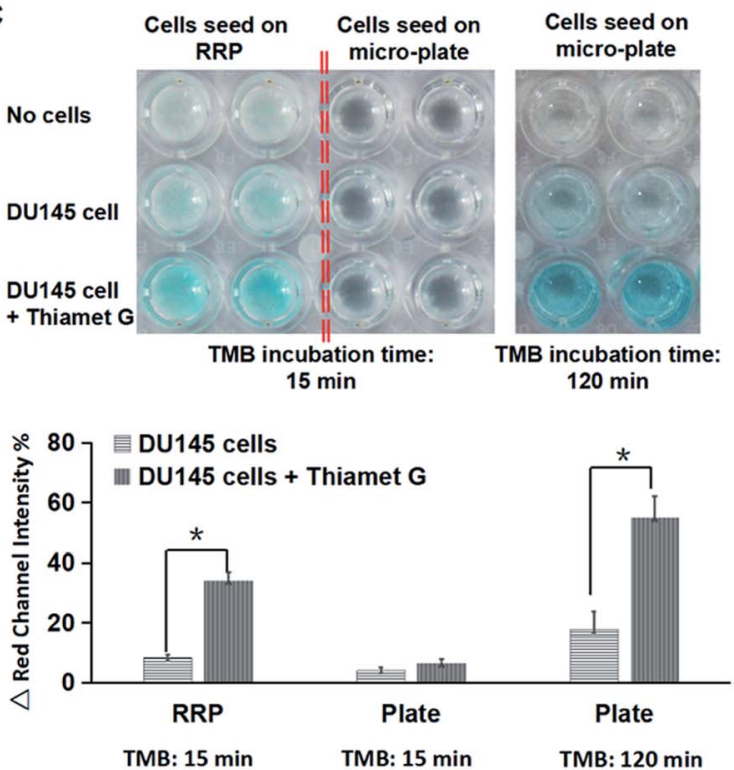

Fig. 6 Cell-immunoassay on raw rice paper. (A) (O-GlcNAc) dynamic cycling in cells. The $O$-GlcNAc transferase (OGT) attaches $O$-GlcNAc to proteins at specific serine or threonine residues. $O$-GlcNAcase hydrolyzes $O$-GlcNAc from proteins. (B) Procedure of cell-immunoassay on rice paper. (C) Image of colorimetric changes from cell-immunoassay. Plot of red channel intensity changes. $*$ denotes $p<0.01$. 
$O$-GlcNAc transferase (OGT) attaches $O$-GlcNAc to proteins, whereas O-GlcNAcase (OGA) hydrolyzes O-GlcNAc from proteins. The two enzymes often occur within the same complex and are therefore highly regulated in controlling $O$-GlcNAc cycling (Fig. 6A).$^{18,19}$ It is believed that $O$-GlcNAc is particularly relevant to chronic human diseases, including diabetes, cardiovascular disease, and cancer. Therefore, it is very important to characterize the level of $O$-GalNAc expressed by cells. Thiamet $\mathrm{G}$ can inhibit the function of OGA to increase the level of $O$-GalNAc. ${ }^{20}$ In this study, to demonstrate the potential of rice paper as a substrate for cell based cell analysis, tumor cell was seeded on rice paper and a subsequent immunoassay for studies of cellular $O$-GalNAc was conducted (Fig. 6B). The last step of cell immunoassay is adding chromogenic substrate TMB to visually characterize the amount/concentration of the $O$ GalNAc target. A stronger blue intensity appears from the test, which indicates that higher amount of $O$-GalNAc is expressed by the cells. The results show that after $15 \mathrm{~min}$ of incubation of TMB, a visible blue colour can be observed from a setting that cells were seeded on raw rice paper. Moreover, the on-paper immunoassay shows that the OGA inhibitor thiamet-G can increase the $O$-GlcNAc protein level in prostate cancer cells because a strong blue was witnessed (Fig. 6C). Apparently, compared to the cell assay performed in a $2 \mathrm{D}$ flat micro-well, a higher colorimetric signal is seen in rice paper-based assays after 15 min incubation with TMB substrate. The changes of colorimetric intensity analysed by ImageJ software (NIH, USA) further proves that inhibitor Thiamet $G$ can increase the expression of $O$-GlcNAc. Moreover, a blue colorimetric change can be observed from cell-immunoassay from a 2D-culture plate after a longer TMB incubation time, indicating that the higher surface area of rice paper can support anchoring and growth of more cells to enhance the signal of cell-based assay. Immunoassays on rice paper confirm that rice paper is a suitable candidate for cell-based paper assays.

\section{Conclusions}

For the first time, Chinese calligraphy paper, also known as rice paper, was evaluated for its potential in building paper-based analytical platforms for cell-based assays. The XRD and FTIR characterization revealed that the component of rice paper is pure cellulose. The chemical and physical features of rice paper were comparable with the current standard (Whatman filter paper). The cell compatibility of rice paper was evaluated by LDH release assay and WST-1 cell growth assay. The results demonstrated that rice paper exhibited better cell compatibility compared with Whatman brand filter and lens paper. This cellfriendly environment was further confirmed by observing anchoring and spreading of cells on rice paper fibers. The potential of rice paper for cell-based analysis was demonstrated by testing $O$-GlcNAc protein level in prostate cancer cells. Encouragingly, the price of rice paper is only one percent of that of Whatman filter paper. In addition, the thickness of rice paper varies (60-120 $\mu \mathrm{m})$, offering more selections for customized applications. The processibility of rice paper and on-paper immunoassays demonstrate its strengths as a low-cost and versatile substrate for paper-based biological devices.

\section{Conflicts of interest}

There are no conflicts to declare.

\section{Acknowledgements}

This study is financially supported by the National Key Scientific Guan Instrument and Equipment Development Projects of China under contract No. 2013YQ03062909, National Science Foundation of China (No. 21375108, 31671037 and 21475106) and the Fundamental Research Funds for the Central Universities (XDJK2015B020, XDJK2016A010).

\section{References}

1 Y.-C. Chen, X. Lou, Z. Zhang, P. Ingram and E. Yoon, Sci. Rep., 2015, 5, 12175.

2 A. W. Martinez, S. T. Phillips, M. J. Butte and G. M. Whitesides, Angew. Chem., Int. Ed., 2007, 46, 13181320.

3 N. R. Pollock, J. P. Rolland, S. Kumar, P. D. Beattie, S. Jain, F. Noubary, V. L. Wong, R. A. Pohlmann, U. S. Ryan and G. M. Whitesides, Sci. Transl. Med., 2012, 4, 152 ra129.

4 A. W. Martinez, S. T. Phillips, G. M. Whitesides and E. Carrilho, Anal. Chem., 2010, 82, 3-10.

5 Y. Zhang, P. Zuo and B.-C. Ye, Biosens. Bioelectron., 2015, 68, 14-19.

6 Y. Li, Y. Lu, Q. Chen, Y. Kang and L. Yu, Biomed. Microdevices, 2017, 19, 54.

7 R. Derda, A. Laromaine, A. Mammoto, S. K. Tang, T. Mammoto, D. E. Ingber and G. M. Whitesides, Proc. Natl. Acad. Sci. U. S. A., 2009, 106, 18457-18462.

8 G. Camci-Unal, D. Newsome, B. K. Eustace and G. M. Whitesides, Adv. Healthcare Mater., 2016, 5, 641-647.

9 B. Mosadegh, M. R. Lockett, K. T. Minn, K. A. Simon, K. Gilbert, S. Hillier, D. Newsome, H. Li, A. B. Hall and D. M. Boucher, Biomaterials, 2015, 52, 262-271.

10 L. Wang, C. Xu, Y. Zhu, Y. Yu, N. Sun, X. Zhang, K. Feng and J. Qin, Lab Chip, 2015, 15, 4283-4290.

11 K. F. Lei and C.-H. Huang, ACS Appl. Mater. Interfaces, 2014, 6, 22423-22429.

12 G. Camci-Unal, A. Laromaine, E. Hong, R. Derda and G. M. Whitesides, Sci. Rep., 2016, 6, 27693.

13 F. d. r. Deiss, A. Mazzeo, E. Hong, D. E. Ingber, R. Derda and G. M. Whitesides, Anal. Chem., 2013, 85, 8085-8094.

14 K. Ng, B. Gao, K. W. Yong, Y. Li, M. Shi, X. Zhao, Z. Li, X. Zhang, B. Pingguan-Murphy, H. Yang and F. Xu, Mater. Today, 2017, 20, 32-44.

15 Y.-H. Chen, Z.-K. Kuo and C.-M. Cheng, Trends Biotechnol., 2015, 33, 4-9.

16 C. Tyagi, L. K. Tomar and H. Singh, J. Appl. Polym. Sci., 2009, 111, 1381-1390.

17 L.-H. Fu, B. Liu, L.-Y. Meng and M.-G. Ma, Mater. Lett., 2016, 171, 277-280. 
18 T. P. Lynch, C. M. Ferrer, S. R. Jackson, K. S. Shahriari, K. Vosseller and M. J. Reginato, J. Biol. Chem., 2012, 287, 11070-11081.

19 Y. Fardini, V. Dehennaut, T. Lefebvre and T. Issad, Front. Endocrinol., 2014, 4, 99.
20 S. A. Yuzwa, M. S. Macauley, J. E. Heinonen, X. Shan, R. J. Dennis, Y. He, G. E. Whitworth, K. A. Stubbs, E. J. McEachern and G. J. Davies, Nat. Chem. Biol., 2008, 4, 483-490. 